\title{
Effective Parental Monitoring: As Determinant of Conduct Disorder among Children
}

\author{
Momina Abid, Sidra Liaquat \\ Department of Applied Psychology, Bahauddin Zakariya University, Multan, PAKISTAN \\ *Corresponding Contact: \\ Email: Mominaabid11@gmail.com \\ Cell Phone: +923320797788
}

\begin{abstract}
Parental monitoring is important to help comprehending the conduct problems with children; it truly is widely recognized being a possibility element for the development regarding child as well as teenage conduct problems. Current study was directed to examine relationship between parental monitoring and conduct disorder among children. The sample of 100 children (50 boys and 50 girls) was select randomly and their mothers were approached from different schools of Multan. Disruptive Behavior Disorder Rating Scale (Malik, T.A, 2011) and Parental Monitoring Scale (Capaldi\& Patterson, 1989) were used. Research finding showed that parental monitoring has significant effect on conduct disorder. Findings of research study depicted that a significant negative correlation between parental monitoring and conducts disorder. The finding depicted to socioeconomic status showed that children with high and low socioeconomic status have significant differences on the level of parental monitoring and conduct disorder. The findings pertaining to educational differences showed that educated and uneducated mother of children have significant differences on the level of parental monitoring and conduct disorder. The findings showed that mother's work status has significant differences on the level of parental monitoring and conduct disorder among children and the findings pertaining that mother's age have significant differences on the level of parental monitoring and conduct disorder.
\end{abstract}

Keywords: Effective Parental Monitoring, Conduct Disorder, Conduct Problems, Disruptive Behavior

9/10/2015

Source of Support: Nil, No Conflict of Interest: Declared

How to Cite: Abid M. and Liaquat S. 2015. Effective Parental Monitoring: As Determinant of Conduct Disorder among Children $A B C$ Journal of Advanced Research, 4, 107-114.

This article is is licensed under a Creative Commons Attribution-NonCommercial 4.0 International License. Attribution-NonCommercial (CC BY-NC) license lets others remix, tweak, and build upon work non-commercially, and although the new works must also acknowledge \& be non-commercial.

\section{INTRODUCTION}

As children approach adolescence, they, quite naturally, tend to spend more time in unsupervised activities, often only in the company of friends. This lack of parental supervision has been found to correlate strikingly with less positive outcomes. Parental monitoring is a prominent component that can affect the conduct problems among children and adolescent and their disruptive behavior. In western culture most of 
researches had been conducted on parental monitoring and conduct problems among children. The present research aimed to determine the relational aspects of parental monitoring and conduct disorder among children in Pakistan especially in Multan.

\section{Parental monitoring}

Parental monitoring has a broad theoretical background for making psychological concepts as behavioral problems and sociological as "juvenile delinquency" (Loeber and Dishion, 1983 and Patterson, 1982). Parental monitoring is defined as a set of attributes and behaviors, parental involvement in the care and supervision of the actions of children, their behaviors, fate, activities, and adaptations (Dishion\& McMahon, 1998). The term "Parental monitoring", commonly defined as tendency of antisocial children's parents watch or not to supervise the activities of children (Patterson, 1982). Parental monitoring environments at home, school, and community children, configure and provides monitoring of child behavior in these environments. From infancy to young adult parental monitoring plays an important role and should be developing, contextual and culturally appropriate.

\section{Conduct Disorder}

Conduct disorder refers to childhood and adolescence violation of social norms, rules, rights of others, and frequently violation of behavioral pattern. Children with this disease are cruel, impulsive, can be described as aggressive and controlling. Conduct disorder is sort of antisocial behaviors as, bullying in general, theft, vandalism and cruelty. Research has explored that Parental monitoring has individual differences in the methods of parental supervision correlates with antisocial behavior among boys (Patterson \&Stouthamer-Loeber, 1984). Parental monitoring has a direct effect (Patterson \&Dishion, 1985), has an indirect effect on delinquent behavior and poor parental supervision, has emerged as an important factor in whether children start deviating peer networks or peers with delinquent behavior (Dishion et al., 1991).

Previous researches on parental monitoring base on clinical observations and case studies found that parents with conduct disordered children often fail to monitor, track, and fail to set rules about the behavior and activities of their children. (Glueck and Glueck, 1950; Hirschi, 1969; Patterson, 1982).Researches (Crouter and Head, 2002; Dishion and McMahon 1998; Sampson and Laub, 1994) explored a consistent relationship between parents and monitoring of children and youth behavioral problems. Inadequate parent tracking has also been identified as the best forecaster of youngsters anti-social actions in comparison to other parent behavior(Loeber and Dishion, 1983; Loeber and Stouthamer-Loeber, 1984).

Another study by Kelso (1986) found that students have more symptoms, the greater the likelihood of behavioral disorder will continue. Among the factors that predict the number of symptoms was persistent symptoms of antisocial or aggressive, including the shooting put an early age from the beginning, and abnormal family. In-depth study on African American sample was done and research analysis predicted that weak parental discipline and parental monitoring in the age of $4 \frac{1}{2} 2$ was reliable independent predictors for behavior problems for boys and girls. Parental monitoring was mediated by parental control with child behavior problems later on, by choosing education schools with high-risk children and parents household income pre-school behavior problems were mediated by the parents of the child discipline and control (Kilgore, Kim; Snyder, James; Lentz, Chris, 2000). Factors associated with risk behavior of adolescents are essential for developing effective prevention strategies. Some risk factors were identified, including family background; but there are few studies that have examined the effect of parental control. (Ralph et al., 2001). 


\section{Objectives}

- To investigate the impact and correlational aspects of parental monitoring and conduct disorder among children.

- To investigate parental monitoring and conduct disorder in term of gender, socioeconomic, mother age, mother education, mother work status among children.

\section{Hypothesis}

- Parental monitoring will significantly affect/impact on Conduct disorder among children.

- Parental monitoring and Conduct disorder will negatively correlate among children.

- Parental monitoring and Conduct disorder will vary in term of socioeconomic, mother age, mother education, mother work status among children

\section{MetHOD}

The present research was done into two phases; phase-I was a translation of the Parental Monitoring Scale (as a pilot study) and Phase-II wasbased on main research study. This article explains the findings of a main study.

\section{Participant}

The sample were consists of 100 children and their mothers. Randomly selected sample from different schools of Multan. Parents and children were included in the study those who willing to participate in the study.

\section{Instruments}

Two Instruments were used in the research.

1. Disruptive Behavior Disorders Rating Scale

2. Parental Monitoring Instrument

\section{Disruptive Behavior Disorders Rating Scale}

Disruptive behavior disorder rating scale was developed by (Pelham, Gnagy, Greenslade, and Milich, 1992). Urdu version of Disruptive behavior disorder rating scale translated by Malik, T.A. (2011) was used. The particular DBD Rating Scale can be consists of 45 items addressing signs and symptoms connected with Hyperactivity Disorder (ADHD), Oppositional defiant disorder (ODD), and Conduct Disorder (CD). Participants tend to be questioned to indicate no matter if trouble behaviors take place in these types of predicaments and also, if that's the case, in order to price your extent. Summary ratings created because of the DBD Rating Scale consist of variety of signs and symptoms and an extent credit score (sum of all scores). Principal caregivers (mothers) completed DBD Rating Scale. Subscale conduct disorder was used in this research. Items no 1-15 were used to measure Conduct disorder in this scale.

Response options and Weightage: there is 4-point rating scale with $0=\mathrm{NEVER}, 1$ Sometimes, $2=$ Often, $3=$ Very Often.Simply count the number of yes answers and average score was calculated

\section{Parental Monitoring Instrument}

Capaldi and Patterson (1989) designed as well as validated the Parental Monitoring Instrument (MPI), in order to gauge personal differences throughout Parental monitoring. Urdu translation and validation of Parental Monitoring scale was done by researcher before the study. Each item is scored on five-point likert scale, higher score signifying a higher recorded level of parental monitoring. 


\section{Procedure}

Information has been accumulated by using survey questionnaire, given to help children and their mother involving diverse educational institutions involving Multan. Information was collected to different age group children (3 to 12). The questionnaire consisted of 2 variables DBD Parent / Teacher Rating Scale and Parental Monitoring Instrument in the booklet from along with consent form and demographic information. These folks were informed with regards to the purpose of research and have been directed how to populate this weighing scales. Participants have been advised to help all the items seriously and have been advice in which responses could stay anonymous. Participants have been likewise provided confidence in which info would be discreet. SPSS 17 version (Statistical Package for Social Sciences) has been used for the descriptive and inferential statistical analysis of the data collected from the parents and their children.

\section{RESULTS}

\section{Table 1}

Regression Analysis showing Impact of Parental Monitoring on Conduct Disorder

\begin{tabular}{|l|c|c|c|c|c|}
\hline Predictor & $\mathrm{B}$ & Std. Error & Beta & $\mathrm{t}$ & $\mathrm{p}$ \\
\hline (Constant) & 41.161 & .883 & & 46.628 & $.000^{* * *}$ \\
\hline Conduct Disorder & -1.356 & .259 & -.362 & -5.242 & $.000^{* * *}$ \\
\hline
\end{tabular}

Note. $R^{2}=0.714$, Adjusted $R^{2}=0.702,(\mathrm{~F}(4,95)=51.217, * * * \mathrm{p}<0.001$

Table 1 Regression analyzes revealed that parental monitoring have a significant impact on conduct disorder.

Table 2

Correlations Matrix on the scores of Parental Monitoring and Conduct Disorder among Children

\begin{tabular}{|c|c|c|c|}
\hline Scale & Parental Monitoring & Conduct Disorder & \\
\hline Parental Monitoring & 1 & $-.694^{* *}$ & \\
\hline Conduct Disorder & & 1 & \\
\hline
\end{tabular}

Note. $\mathrm{N}=100 .{ }^{* *} \mathrm{p}<0.01$

Table 2 demonstrates that asignificant negative relationship between parental monitoring and conduct disorder. Values indicate that parental monitoring and conduct disorder are negative related to one another. It delineates that as parental monitoring in children will increase conduct disorder will decrease.

Table 3

Socioeconomic StatusDifferences on the scale of Parental Monitoring Instrument among Children

\begin{tabular}{|c|c|c|c|c|c|c|}
\hline Socioeconomic Status & $N$ & $M$ & $S D$ & $t(98)$ & $p$ & Cohen's d \\
\hline Low & 53 & 25.55 & 8.375 & & & \\
\hline & & & & -7.172 & $.000^{* * *}$ & -1.45 \\
\hline High & 47 & 35.77 & 5.333 & & & \\
\hline
\end{tabular}

Note: $\mathrm{N}=100,{ }^{* * *} p<0.001$

Table 3 disclosed that significant differences in the two groups of Socioeconomic Status low and high $\left(\mathrm{t}=-7.172, \mathrm{df}=98,{ }^{* * *} \mathrm{p}<0.001\right)$. The results indicated critical distinction in the level of parental monitoring among children. It accepts a hypothesis.

\section{Table 4}

Socioeconomic Status Differences on the scale of Conduct Disorder among Children

\begin{tabular}{|c|c|c|c|c|c|c|}
\hline Socioeconomic Status & $N$ & $M$ & $S D$ & $t(98)$ & $p$ & Cohen's d \\
\hline Low & 53 & 3.74 & 2.263 & & & \\
\hline High & & & & 6.704 & $.000^{* * *}$ & 1.35 \\
\hline
\end{tabular}

Note: $\mathrm{N}=100,{ }^{* * *} p<0.001$ 
Table 4 reveals that a significant differences in two groups of Socioeconomic Status low and high $\left(t=6.704, d f=98,{ }^{* * *} p<0.001\right)$. The results showeda significant difference in the level of conduct disorder among children. It accepts a hypothesis.

Table 5

Mother EducationDifferences on the scale of Parental Monitoring Instrument among Children

\begin{tabular}{|c|c|c|c|c|c|c|}
\hline Mother's Education & $N$ & $M$ & $S D$ & $t(98)$ & $p$ & Cohen's d \\
\hline Uneducated & 43 & 25.40 & 8.177 & & & \\
\hline & & & & -5.640 & $.000^{* * *}$ & -1.14 \\
\hline Educated & 57 & 34.09 & 7.192 & & & \\
\hline
\end{tabular}

Note: $N=100,{ }^{* * *} p<0.001$

Table 5 reveals that a significant differences inside two groups of Mother's Education educated and uneducated $\left(t=-5.640, d f=98,{ }^{* * *} p<0.001\right)$. The results showed the significant difference in the level of parental monitoring in term of mother education among children. It accepts the hypothesis.

\section{Table 6}

Differences of Two Groups of Mother Education the scale of Disruptive Behavior Disorder Scale $\mathcal{E}$ subscale Conduct Disorder among Children

\begin{tabular}{|c|c|c|c|c|c|c|}
\hline Mother's Education & $N$ & $M$ & $S D$ & $t(98)$ & $p$ & Cohen's d \\
\hline Uneducated & 43 & 3.63 & 2.411 & & & \\
\hline Educated & & & & 4.558 & $.000^{* * *}$ & 0.92 \\
\hline
\end{tabular}

Note: $N=100,{ }^{* * *} p<0.001$

Table 6 uncovered that considerable differences from the two categories of Mother's Education educated and uneducated mothers $(\mathrm{t}=4.558, \mathrm{df}=98, * * * \mathrm{p}<0.001)$. The results indicated a significant difference in the level of conduct disorder in term of mother education among children. It accepts a hypothesis.

Table 7

Differences of Two Groups of Mother work statuson the scale of Parental Monitoring Instrument among Children

\begin{tabular}{|c|c|c|c|c|c|c|}
\hline Work Status & $N$ & $M$ & $S D$ & $t(98)$ & $p$ & Cohen's d $^{\prime}$ \\
\hline Working & 62 & 27.84 & 8.865 & & & \\
\hline & & & & -3.930 & $.000^{* * *}$ & -0.79 \\
\hline Non-working & 38 & 34.45 & 6.845 & & & \\
\hline
\end{tabular}

Note: $N=100,{ }^{* * *} p<0.001$

Table 7 reveals that a significant differences in the two groups of Mother's work status working and non-workingmothers $\left(t=-3.930, d f=98,{ }^{* * *} p<0.001\right)$. The results showedthe significant difference in the level of parental monitoring in term of mother work status among children. It accepts the hypothesis.

Table 8

Differences of Mother work statuson the scale of Conduct Disorder among Children

\begin{tabular}{|c|c|c|c|c|c|c|}
\hline Work Status & $N$ & $M$ & $S D$ & $t(98)$ & $p$ & Cohen's d \\
\hline Working & 62 & 3.10 & 2.427 & & & \\
\hline & & & & 3.377 & $.001^{*}$ & 0.68 \\
\hline Non-working & 38 & 1.55 & 1.826 & & & \\
\hline
\end{tabular}

Note: $N=100,{ }^{*} p>0.05$

Table 8 reveals thatsignificant differences in the two groups of Mother's work status working and nonworkingmothers $\left(t=3.377, d f=98,{ }^{*} p>0.05\right)$. The results showed the significant difference in the level of conduct disorder in term of mother work status among children. It accept hypothesis. 


\section{Discussion}

Parental monitoring is one of the significant factors that influence the child's development through its various agents. Evidence has suggested that poor parental monitoring has also been identified as the best predictor of adolescent antisocial behavior as compared to other parenting behaviors (Loeber and Dishion, 1983; Loeber and Stouthamer-Loeber, 1987). The primary objective of the present research was to study the relationship between parental monitoring and conduct disorder among children. It was also intended to investigate parental monitoring as predictive of children's conduct disorder. The hypothesis about the significant negative relationship between parental monitoring and conduct disorder were supported. Children under high parental monitoring were perceived as low on conduct disorder by parents. The findings are in line with previous studies showing a significant negative relationship between parental monitoring and conduct disorder (Loeber and Dishion, 1983; Loeber and Stouthamer-Loeber, 1987). Regression analysis showed that parental monitoring as a significant predictor of conduct disorder. Poor parental monitoring has also been identified as the predictor of antisocial behavior among adolescent (Loeber and Dishion, 1983; Loeber and Stouthamer-Loeber, 1987).

Parental monitoring and conduct disorder will vary in term of socioeconomic status among children. Socioeconomic status play a significant role in parental monitoring and conduct problems Children with low socioeconomic status has less parental monitoring and suffering from high conduct disorder. Previous research studies support this hypothesis low family income has been associated with early sexual activity, cigarette smoking, adolescent pregnancy, and (conduct problems) delinquency (National Research Council 1995; Blum et al. 2000). But the children's who belongs to high socioeconomic status has a high level of parental monitoring and a low level of conduct disorder. The finding of the present research has supported the previous evidence which shows Parents' ability to manage successfully their children's' chronic conditions and is positively related to family income (Thompson, Auslander, and White 2001). Children with low socioeconomic status had high conduct problems. Literature review support that Bird, (2001) research findings revealed that the conduct disorder is more common among children who are from low socio-economic backgrounds and who have parents with antisocial personality disorder and alcohol dependence. It's supported this hypothesis.

It was hypothesized that parental monitoring and conduct disorder will vary in term of mother education among children. Mother education is an important phenomenon to show the relation between parental monitoring and conduct disorder. Results of the present study shows that children who belong to educated mothers had experience high parental monitoring and fewer conduct disorder. Uneducated mother's child experience low parental monitoring and high conduct disorder. Another assumption of this research is "Parental monitoring will vary in term of mother education among children". Our results depict significant difference in parental monitoring in term of mother education. It's also showed that level of parental monitoring is high in educated mothers than uneducated mothers of children. One of the interesting finding of this research is parental monitoring and conduct disorder will vary in term of mother's working status among children". It shows the difference in the level of parental monitoring in working and non-working mothers among children. Results indicate that level of parental monitoring is high in non-working mothers as compared to working mothers. Working mothers cannot spend more time with their children, in contrast non-working mother spend lot of time with their children, and they are the caretaker of their own child. It shows the difference in the level of conduct disorder in working and non-working mothers among children. Results indicate that level of conduct disorder is high among working mothers of children than nonworking mothers of children. The result of this study supported the hypothesis. 


\section{CONCLUSION}

The present study was aimed to explore the correlational aspects of parental monitoring and conduct disorder and impact of parental monitoring on conduct disorder among Children. Findings of the study represent that significant impact of parental monitoring on conduct disorder and negative correlation of parental monitoring and conduct disorder. As caretaker and mothers will increase parental monitoring, it will decrease conduct disorder among children. Parental monitoring is high in children with high socioeconomic status, conduct disorder is high in children with low socioeconomic status, Mother education play an important role in parental monitoring and conduct disorder among children, result showed the difference in the level of parental monitoring in working and non-working mothers among children, level of parental monitoring is high in non-working mothers than working mothers and conduct disorder is high working mothers than non-working.

\section{Implementations}

Parental monitoring is widely recognized as a risk factor for the development of child and adolescent. For the termination of conduct problems, Effective parental monitoring is necessary thing. In Pakistan or especially in the southern areas of country like Multan it is one of the most ignored factors in a child development which is resulted in behavioral and conduct problems in latter age. Parental awareness, Positive Parenting Program and Parental Management Training are examples of existing broad parenting interventions that target improvements in parental monitoring. As need of time, education of mothers and caretaker (especially in schools) should insure for a better behavioral training of children. Working mothers should be facilitated with their family time at their workplace. Behavioral family intervention programs are to provide parents with the support, strategies, and skills necessary to enhance the general functioning of the family. Important parenting skills include; effective parental supervision \& monitoring, appropriate discipline, realistic expectations of child behavior, and warm and supportive parent child relationships. Study suggests that Encouraging parents to know where their children is, knowing their friends, and having a check in time may decrease conduct problems. This study also suggests that school counselors and teachers should focus on increasing levels of parental monitoring in order to decrease disruptive behaviors among children.

\section{Limitations}

Limitations also exist when it comes to measures of critical independent variables along with the theoretical frameworks we were looking at intended to stand for.

- Sample composition and Participants attended grades 1-5. This was a relative small sample size.

- Research had been performed solely in a variety of regions of Multan.

- Another impediment of this study was the utilization of report toward oneself instruments. This researcher can just expect that members reported data as precisely as their understanding of their encounters permitted.

\section{Suggestions}

Following suggestions should follow by future researchers:

- The sample size ought to be vast and across the nation exploration is required

- This examination has established the framework for future studies to inspect the circumstances and end results between parental monitoring and behavior issues other intervened components ought to investigate in future exploration.

- More demographic variables including parents' personality, institution setting, hostility, bulling and the like must review. 


\section{REFERENCE}

Bird, H. R. (2001).Psychoanalytic perspectives on theories regarding the development of antisocial behavior.Journal of the American Academy of Psychoanalysis, 29(1), 57-71.

Blum RW, Beuhring T, Shew ML, Bearinger LH, Sieving RE, Resnick MD. "The Effects of Race/Ethnicity, Income, and Family Structure on Adolescent Risk Behaviors." American Journal of Public Health.2000;90(12):1879-84. [PMC free article] [PubMed]

Capaldi, D.M., \& Patterson, G.R. (1989).Psychometric properties of fourteen latent constructs from the Oregon Youth Study. New York: Springer-Verlag.

Crouter, A. C., \& Head, M. R. (2002).Parental monitoring and knowledge of children. In M. H. Bornstein (Ed.), Handbook of parenting: Vol. 3: Being and Becoming a parent (2nd ed., pp. 461-483). Mahwah, NJ: Erlbaum.

Dishion, T. J., \& McMahon, R. J. (1998). Parental monitoring and the prevention of child and adolescent problem behavior: A conceptual and empirical formulation. Clinical Child and Family Psychology Review, 1, 61-75.

Dishion, T. J., Patterson, G. R., Stoolmiller, M., \& Skinner, M. L. (1991).Family, school, and behavioral antecedents to early adolescent involvement with antisocial peers.Developmental Psychology, 27(1), 172-180.

Glueck, S., \&Glueck, E. (1950).Unraveling juvenile delinquency.New York: The Commonwealth Fund.

Hirschi, T. (1969). Causes of delinquency. Berkeley: University of California Press.

Kelso, J. (1986). Factors which predict the persistence of aggressive conduct disorder. Journal of Child Psychology and Psychiatry and Allied Disciplines; 27(1) 77-86.

Kilgore, Kim; Snyder, James; Lentz, Chris. (2000). Developmental Psychology, Vol 36(6),835-845.

Loeber, R., \&Dishion, T. (1983). Early predictors of male delinquency: A review. Psychological Bulletin, 94, 68-99.

Loeber, R., \&Stouthamer-Loeber, M. (1987). Family factors as correlates and predictors of juvenile conduct problems and delinquency. In M. Tonry\& N. Morris (Eds.), Crime and Justice (Vol. 17, pp. 29-149). Chicago: University of Chicago Press.

Malik, T.A. (2011). Effectiveness of parent training program for treating disruptive behaviors associated with Attention Deficit Hyperactivity Disorder (ADHD).Unpublished Ph.D. Dissertation.National Institute of Psychology, Quaid-i-Azam University, Islamabad, Pakistan.

McMahon, R. J., \& Estes, A. M. (1997). Conduct problems. In E. J. Mash \& L. G. Terdal (Eds.), Assessment of childhood disorders ( $3^{\text {rd }}$ ed., pp. 130-193). New York:Guilford Press.

National Research Council, Commission on Behavioral and Social Sciences and Education (1995). Losing Generations: Adolescents in High-Risk Settings. Washington, DC: National Academy Press;

Patterson, G. R. (1982). Coercive family process. Eugene, OR: Castalia.

Patterson, G. R., \&Dishion, T. J. (1985).Contributions of families and peers to delinquency.Criminology, 23, 63-79.

Patterson, G. R., \&Stouthamer-Loeber, M. (1984).The correlation of family management practices and delinquency.Child Development, 55, 1299-1307.

Pelham, W. E., Gnagy, E. M., Greenslade, K. E., \&Milich, R. (1992).Teachers' rating of DSM-III-R symptoms for disruptive behavior disorders.Journal of the American Academy of Child and Adolescence Psychiatry, 31, 210-218.

Ralph T. DiClemente, Gina M. Wingood, Richard Crosby, CatlainnSionean, Brenda K. Cobb, Kathy Harrington, Susan Davies, Edward W. (2001). Hook III and M. Kim Oh Pediatrics 2001;107;1363..

Sampson, R. J., \&Laub, J. H. (1994). Urban poverty and the family context of delinquency: A new look at structure and process in a classic study. Child Development, 65, 523-540.

Thompson SJ, Auslander WF, White NH. (2001).“Comparison of Single-Mother and Two-Parent Families on Metabolic Control of Children with Diabetes."Diabetes Care. 24(2):234-8. [PubMed]

Weintraub, K. J., \& Gold, M. (1991).Monitoring and delinquency.Criminal Behaviour and Mental Health, 1, 268-281. 